\title{
Optics developments for ATHENA
}

Bavdaz, Marcos; Wille, Eric; Ayre, Mark; Ferreira, Ivo; Shortt, Brian; Fransen, Sebastiaan; Collon, Maximilien J.; Vacanti, Giuseppe; Barrière, Nicolas; Landgraf, Boris

Total number of authors:

22

Published in:

Optics for EUV, X-Ray, and Gamma-Ray Astronomy IX

Link to article, DOI:

$10.1117 / 12.2530912$

Publication date:

2019

Document Version

Publisher's PDF, also known as Version of record

Link back to DTU Orbit

Citation (APA):

Bavdaz, M., Wille, E., Ayre, M., Ferreira, I., Shortt, B., Fransen, S., Collon, M. J., Vacanti, G., Barrière, N., Landgraf, B., Start, R., van Baren, C., Della Monica Ferreira, D., Massahi, S., Christensen, F., Krumrey, M., Burwitz, V., Pareschi, G., Valsecchi, G., ... Korhonen, T. (2019). Optics developments for ATHENA. In S. L. OD., \& G. P. (Eds.), Optics for EUV, X-Ray, and Gamma-Ray Astronomy IX (Vol. 11119). [111190D] SPIE International Society for Optical Engineering. Proceedings of SPIE - The International Society for Optical Engineering https://doi.org/10.1117/12.2530912

\section{General rights}

Copyright and moral rights for the publications made accessible in the public portal are retained by the authors and/or other copyright owners and it is a condition of accessing publications that users recognise and abide by the legal requirements associated with these rights.

- Users may download and print one copy of any publication from the public portal for the purpose of private study or research.

- You may not further distribute the material or use it for any profit-making activity or commercial gain

- You may freely distribute the URL identifying the publication in the public portal 


\section{Optics developments for ATHENA}

Marcos Bavdaz, Eric Wille, Mark Ayre, Ivo Ferreira, Brian Shortt, et al.

Marcos Bavdaz, Eric Wille, Mark Ayre, Ivo Ferreira, Brian Shortt, Sebastiaan Fransen, Maximilien J. Collon, Giuseppe Vacanti, Nicolas Barrière, Boris Landgraf, Ronald Start, Coen van Baren, Desiree Della Monica Ferreira, Sonny Massahi, Finn Christensen, Michael Krumrey, Vadim Burwitz, Giovanni Pareschi, Giuseppe Valsecchi, Paul Oliver, André Seidel, Tapio Korhonen, "Optics developments for ATHENA," Proc. SPIE 11119, Optics for EUV, XRay, and Gamma-Ray Astronomy IX, 111190D (9 September 2019); doi: 10.1117/12.2530912

SPIE Event: SPIE Optical Engineering + Applications, 2019, San Diego, California, United States 


\title{
Optics Development for ATHENA
}

\author{
Marcos Bavdaz ${ }^{1}$, Eric Wille ${ }^{1}$, Mark Ayre ${ }^{1}$, Ivo Ferreira ${ }^{1}$, Brian Shortt ${ }^{1}$, Sebastiaan Fransen ${ }^{1}$, \\ Maximilien J. Collon ${ }^{2}$, Giuseppe Vacanti ${ }^{2}$, Nicolas M. Barrière ${ }^{2}$, Boris Landgraf ${ }^{2}$, Ronald Start ${ }^{3}$, \\ Coen van Baren ${ }^{4}$, Desiree Della Monica Ferreira ${ }^{5}$, Sonny Massahi ${ }^{5}$, Finn Christensen ${ }^{5}$, Michael \\ Krumrey $^{6}$, Vadim Burwitz ${ }^{7}$, Giovanni Pareschi ${ }^{8}$, Giuseppe Valsecchi ${ }^{9}$, Paul Oliver ${ }^{11}$, André Seidel ${ }^{12}$, \\ Tapio Korhonen ${ }^{13}$

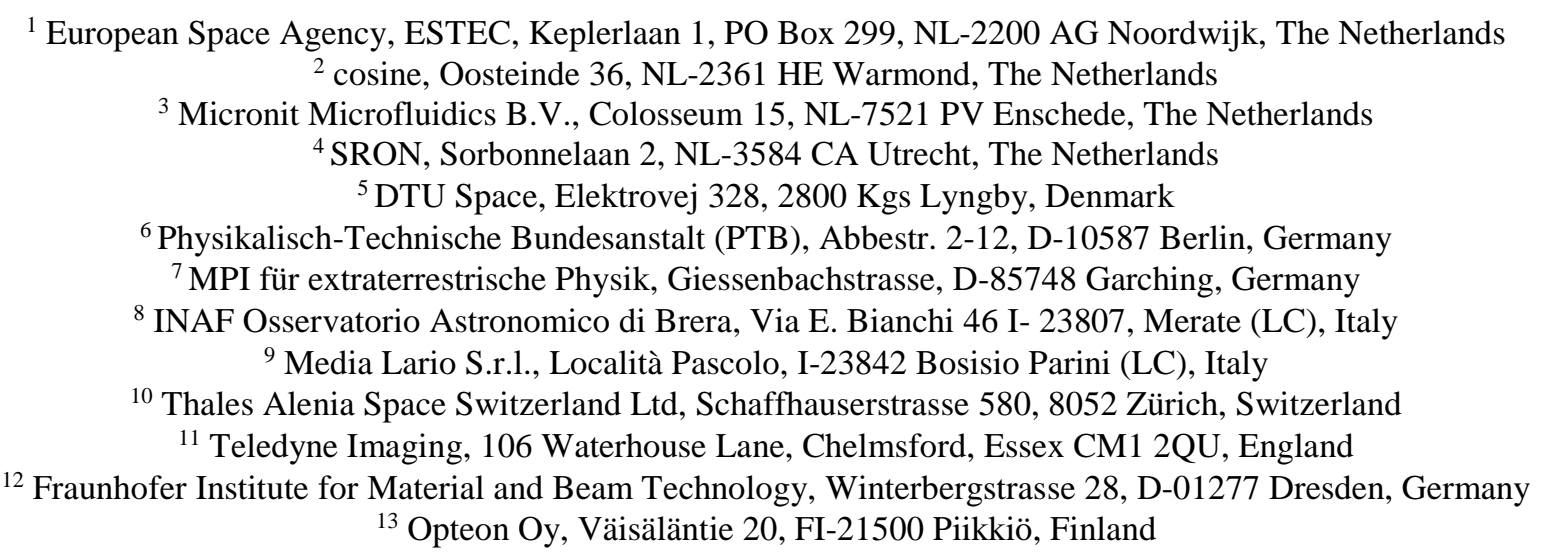

\begin{abstract}
Mission studies and technology preparation for the ATHENA (Advanced Telescope for High ENergy Astrophysics) [15] mission are continuing to progress. The X-ray optics of this future space observatory are based on the Silicon Pore Optics (SPO) technology [6-58], and is being evolved in a joint effort by industry, research institutions and ESA.

The SPO technology benefits from substantial investments made by the semiconductor industry, and spins-in materials, processes and equipment into the development of novel X-ray optics. A comprehensive Technology Development Plan (TDP) is being implemented, funded by ESA and involving a large number of experts in key areas ranging from micro machining of Silicon, over sophisticated automation and robotic systems, to hybrid manufacturing.

The performance, environmental compatibility and serial automated production and testing are being addressed in parallel, aiming at the demonstration of the required technology readiness for the ATHENA Mission Adoption Review (MAR) expected by the end of 2021. A formal Technology Readiness Assessment is in place and is being currently exercised in preparation of the ATHENA Mission Formulation review (MFR). The programmatics for the flight model implementation is being defined in detail, and preparations are starting for the design and implementation of the necessary facilities.
\end{abstract}

An overview of the ATHENA optics technology preparation, the technology readiness assessment and the related activities is provided.

Keywords: X-ray optics, X-ray astronomy, ATHENA, Silicon Pore Optics, X-ray telescopes, X-ray testing, Technology preparation

Optics for EUV, X-Ray, and Gamma-Ray Astronomy IX, edited by Stephen L. O'Dell, Giovanni Pareschi, Proc. of SPIE Vol. 11119, 111190D · C 2019 SPIE · CCC code: 0277-786X/19/\$21 - doi: 10.1117/12.2530912 


\section{DEVELOPING THE LARGEST X-RAY OPTICS EVER BUILT}

The ambitious requirements of the ATHENA mission can only be met with a novel X-ray optics technology. The X-ray optics technologies in operation today, flying on Chandra [59], XMM-Newton [60] and NuSTAR [61], cannot combine the effective area, angular resolution and low specific mass, as necessary to enable the science planned to be done with ATHENA. ESA is therefore evolving the Silicon Pore Optics (SPO) and maturing it to the Technology Readiness Level (TRL) required for the adoption of the mission onto the ESA Science Programme.

A fully funded Technology Plan was elaborated and is being regularly updated to reflect the progress. This plan consists of coordinated activities, which are being implemented by the industry and research institutions in the ESA Member States, in close collaboration with ESA experts. In figure 1 a simplified overview of this ATHENA optics Technology Development Plan (TDP) is provided.

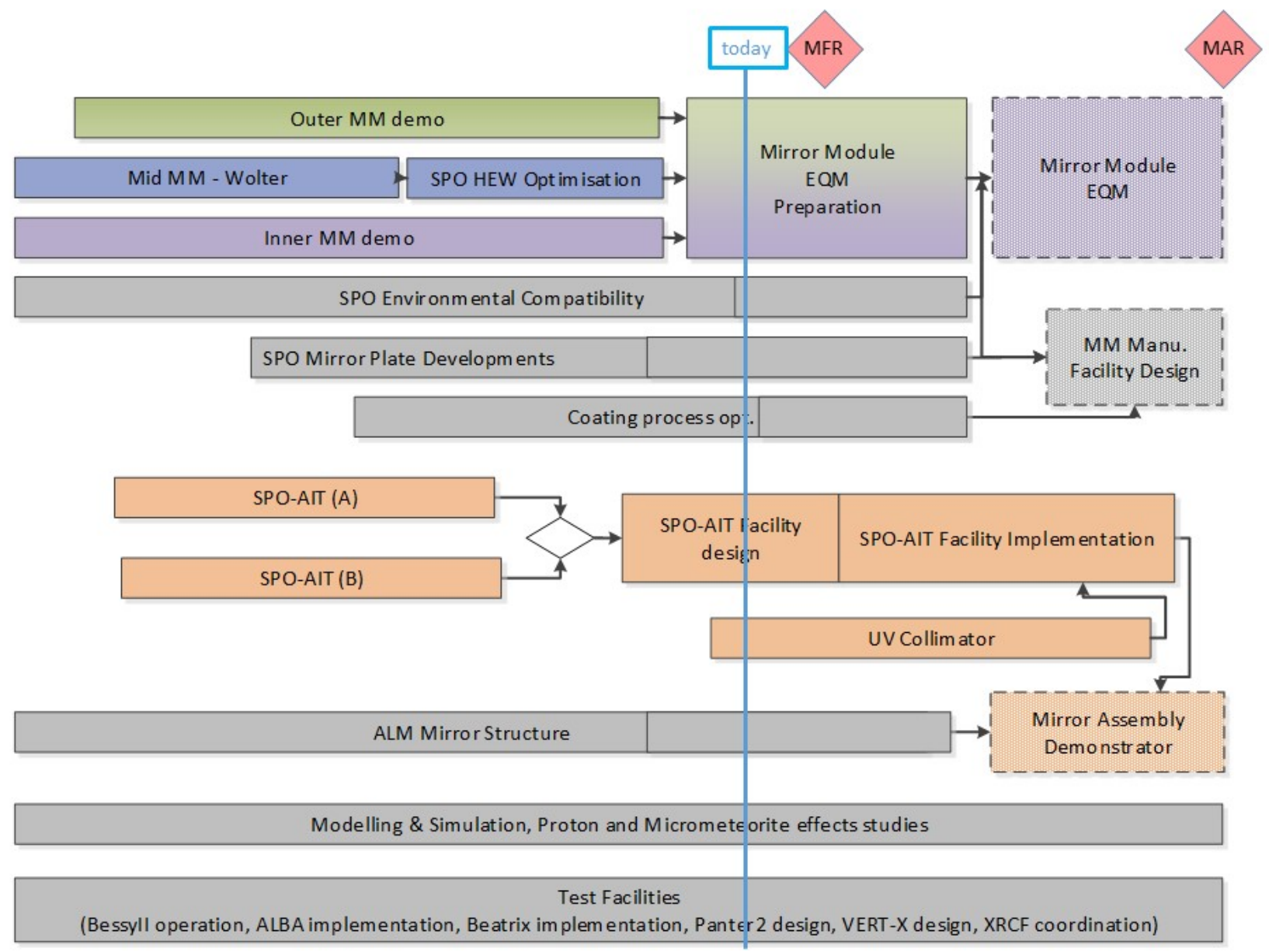

Figure 1: This representation of the ATHENA optics Technology Development Plan (TDP) illustrates the main technology activities running or being implemented (solid lines) or planned (dashed lines). Each of these activities represent an industrial contract between ESA and an industrial consortium, fully funded and led by ESA. The upper group of activities regard the development of the Silicon Pore Optics (SPO) mirror modules. The main activity here targets the improvement of the angular resolution of the mirror modules, and is complemented by the environmental compatibility demonstration and the optimisation of the reflective coatings. The middle group of activities addresses the assembly of the ATHENA Mirror Assembly Module, and includes the implementation of the facility required to precisely mount the flight model mirror modules into the optical bench structure. The bottom group of activities regards computer modelling and the provision of X-ray test facilities. 
The main work targets the SPO mirror modules, improving the angular resolution, demonstrating the environmental compatibility and preparing the large scale production of the about 700 mirror modules required for the flight model optics of ATHENA. Significant progress is being made regarding the optical performance of the SPO optics.

\section{PROGRESS IN OPTICS PRODUCTION AND PERFORMANCE}

The core element of the ATHENA X-ray optics is the SPO mirror module, representing a compact off-axis segment of the ATHENA telescope aperture. These modules consist of two sets of high quality monocrystalline Silicon mirror plates, mounted in tandem to produce a close approximation of the Wolter-Schwarzschild optics. The individual mirror plates are assembled into groups, stacked upon each other with monolithic ribs separating the optical surfaces, and fused to each other by direct silicon bonding. Four stacks of 35 mirror plates each are assembled into each mirror module, employing two lateral invar bracket plates, carefully machined and light-weighted. The stacks of bonded mirror plates are very robust and show a graceful degradation in case of damage, and are attached to the bracket plates via carefully designed glue shimming interfaces. Figure 2 shows two such mirror modules, for the middle and outer radius of the ATHENA aperture. In addition, not shown, mirror modules for the inner-most ATHENA radius are being developed.

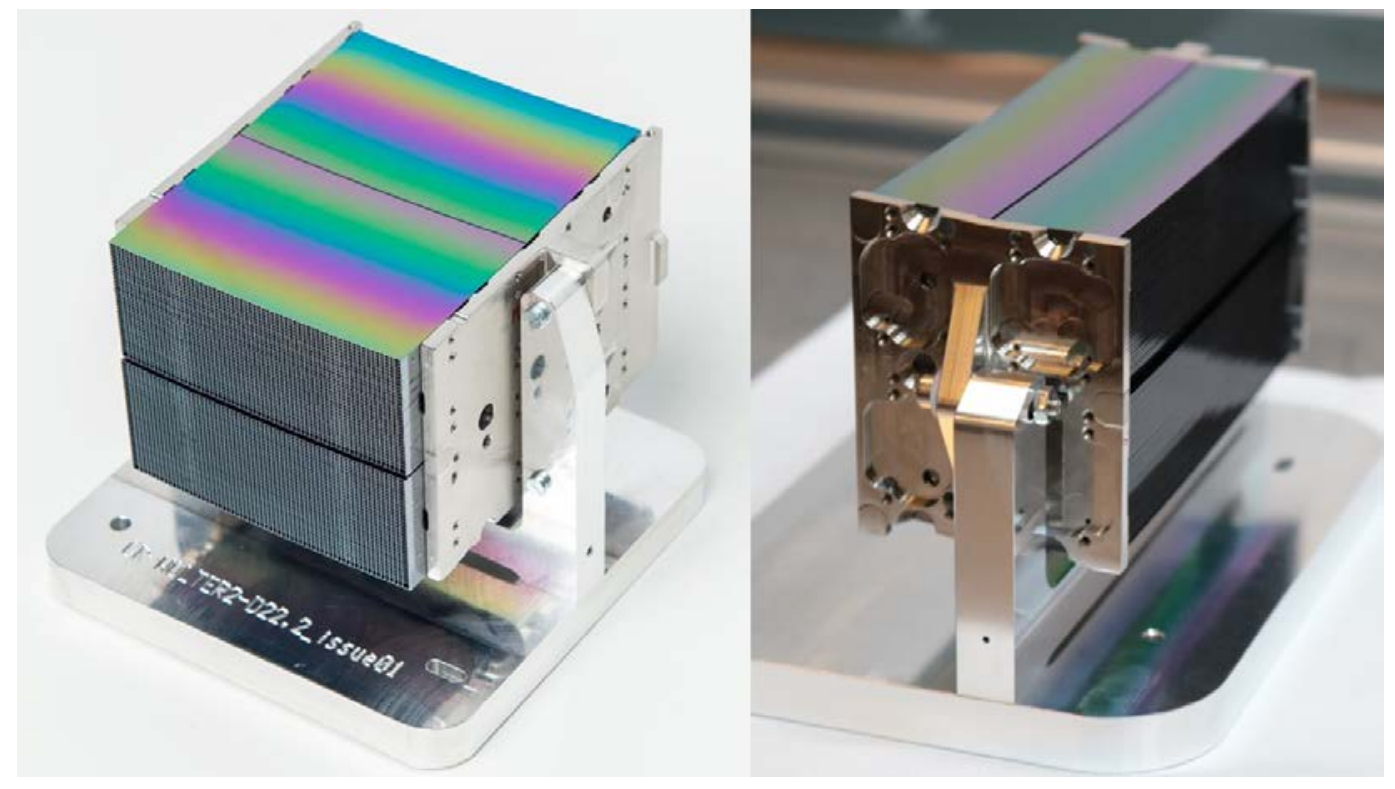

Figure 2: ATHENA mirror modules for the middle (left) and outer (right) radius of the ATHENA aperture. Each mirror module consists of four stacks of monocrystalline silicon, each containing 35 precision machined mirror plates. The four stacks are assembled using two lateral invar brackets. The mirror modules are then installed into the telescope optical bench using 3 dowel pins representing an isostatic mount.

The optical performance is mainly being improved using the middle radius, most representative of the ATHENA mirror modules. In figure 3 the evolution of the X-ray imaging performance, as measured with synchrotron and conventional facilities over time, is shown. The measured Half-Energy-Width (HEW) is plotted against time, spanning about 19 months. Four cases were analysed: full area illumination (100\% of the width), and contiguous sub-apertures covering $70 \%, 30 \%$ and $10 \%$ of the geometric area. The complete height of a mirror plate stack was illuminated, and the optics was mounted in a flight-like configuration.

For all cases the angular resolution improved over time, and while not yet achieving the required resolution (indicated by the blue dashed line), the $10 \%$ area is closing in, being currently at 7.2 arc-seconds. $70 \%$ of the area is already at 10.2 arc-seconds, which is better than the optics flying on Newton, but with a tenth of the mass density. 


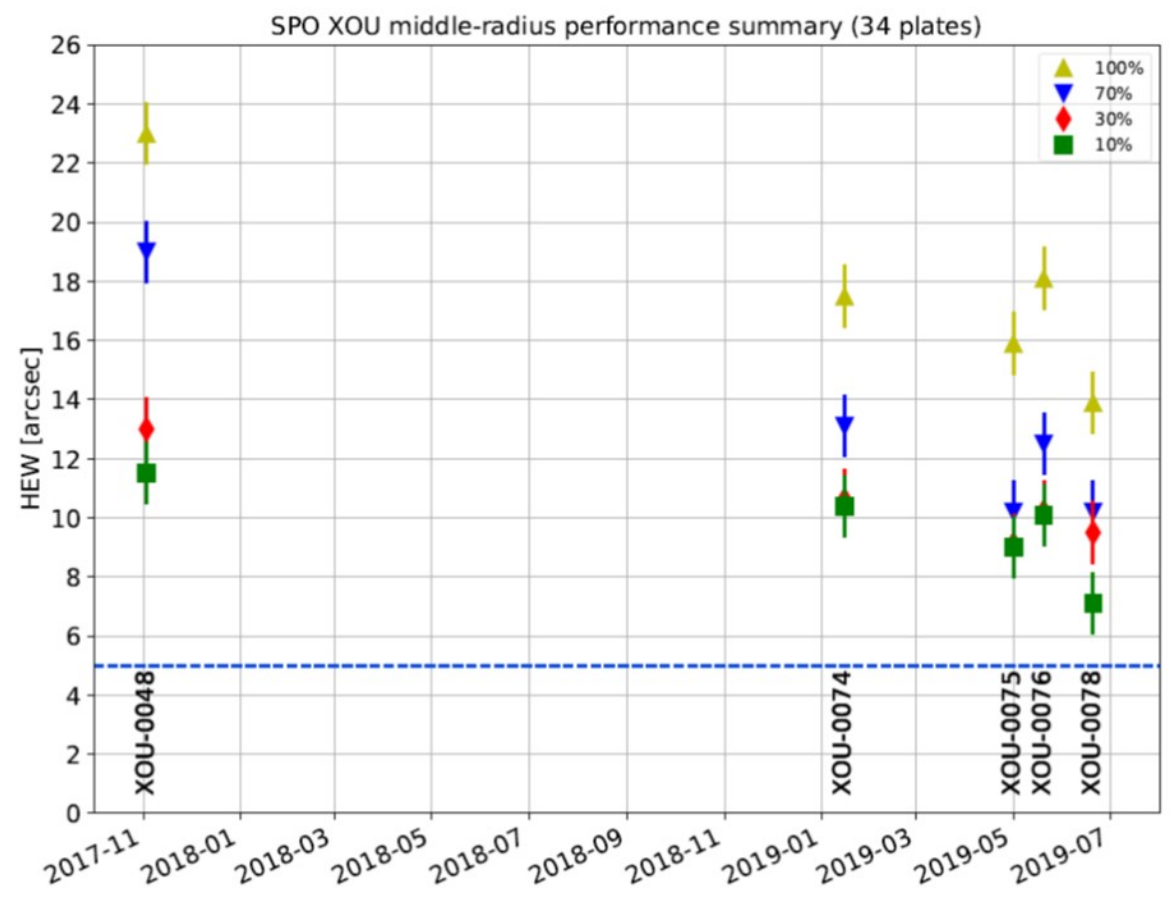

Figure 3: Measured X-ray performance of representatively mounted ATHENA mirror modules. The complete height of a mirror plate stack, comprising 34 mirror plates, is illuminated. Steady improvement of the angular resolution over time is evident, and the performance of the central $70 \%$ of the module width achieved 10.2 arc-seconds. Locally the mirror plate stack pair is much better, with 7.2 arc-seconds for $10 \%$ of the module width. The ATHENA requirement is indicated by the blue dashed line, which should be demonstrated by the Mission Adoption Review (MAR).

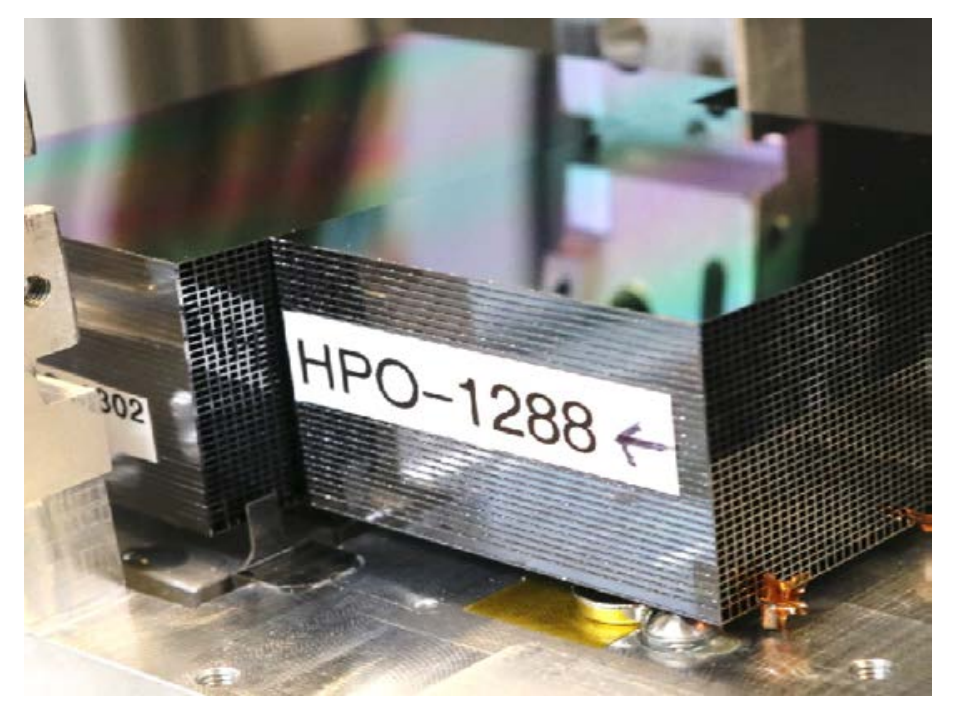

Figure 4: Stacks of bonded mirror plates can be cut, without affecting the figure of the remaining part. Stack HPO-1288 has been cut on both sides, removing the parts showing systematically inferior performance. To the left a standard mirror stack is shown. Removing the outer $10 \mathrm{~mm}$ of each stack is a very effective way to improve the angular resolution of the ATHENA mirror modules. The $70 \%$ points in figure 3 above essentially become the new $100 \%$. 
A key innovation recently introduced into the SPO development is the ability to cut the stack of bonded mirror plates, without affecting the figure of the remaining part of the mirror module. Figure 4 shows a cut stack next a standard one.

This technology allows the removal of the lateral sides of the mirror stacks, thereby removing a large fraction of the figure errors and consequently improving the angular resolution of the resultant optics. Effectively the 70\% performance plotted in figure 3 becomes the new $100 \%$.

In order to maintain the specified mirror module and stack width, extra wide mirror stacks are produced, and in the following $10 \mathrm{~mm}$ on each side is removed, effectively keeping the good part of the stack.

\section{TECHNOLOGY READINESS ASSESSMENTS AND MISSION REVIEWS}

The technology maturation has to be carefully monitored, and the achieved TRL has to be regularly assessed. ESA Science mission candidates have to demonstrate TRL5 (in some cases 6) on the ISO scale [62] by the time of adoption. The Mission Adoption Review (MAR) of ATHENA is expected by Q3 2021, and that is when the critical Technology Readiness Assessment (TRA) will be performed.

The ATHENA Phase A industrial spacecraft contracts are concluding with the Mission Formulation Review (MFR) in Q3 2019, and if successful, the Phase B industrial system study contracts will begin end 2019. While there is no specific requirement on the required TRL to be achieved by MFR, a TRA of the critical technologies is part of this review, with the aim to also verify the completeness, adequacy and consistency of the associated Technology Plan.

Consequently, dedicated Technology Readiness Assessments (TRAs) have been performed (Q2 2019) to provide an objective assessment of the TRL for the different technologies related to the ATHENA optics. As a by-product, these TRAs allowed the identification of any current shortcomings, leading to improvements of the Technology Plan as necessary.

The TRAs therefore were tasked to provide an objective and independent answer to the following three questions:

1. What was the TRL of the different optics technologies at that time?

2. What was the likelihood, assuming the current status \& Technology Plan, of reaching TRL 5/6 by adoption?

3. What changes to the Technology Plan could be proposed that could increase the above likelihood?

For this purpose, a two-stage procedure was created involving a "mapping” and a "review" stage (figure 5).

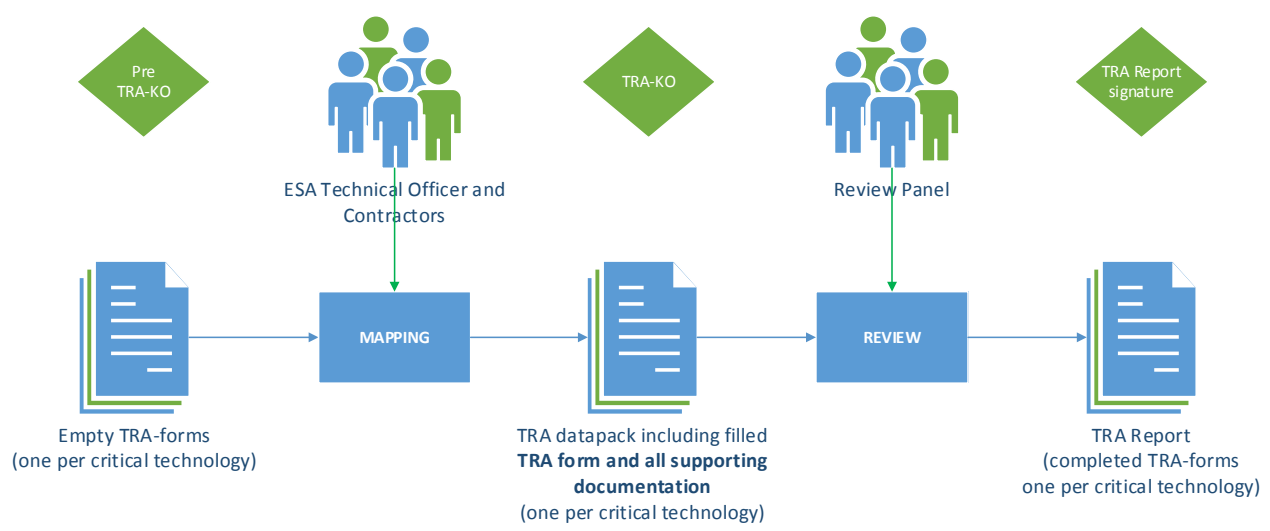

Figure 5: Technology Readiness Assessment (TRA) procedure consisting of a “mapping” and a “review” stage. 
During the "mapping" stage, the ESA technical officer(s) and/or the contractor(s) in charge of a particular technology prepared a data pack consisting of a filled TRA form and supporting documentation to summarise the status of the technology in an objective way.

Then, an independent review panel performed the "review stage" whose goal was to answer the three questions above. The answers to a particular TRA form were scrutinised taking also into account the supporting documentation. Discussions were held between the ESA technical officer(s) and the review panel to converge towards a consolidated version of the TRA form.

Finally, a TRA Report was generated that included the consolidated TRA form answering the question 1 above. Questions 2 and 3 were addressed in the report in more subjective way.

The critical aspects of the ATHENA optics have been organised in a tree structure to map them into products at different levels. Four different levels have been defined: Plate, Stack, Mirror Module and Mirror Assembly (figure 6).

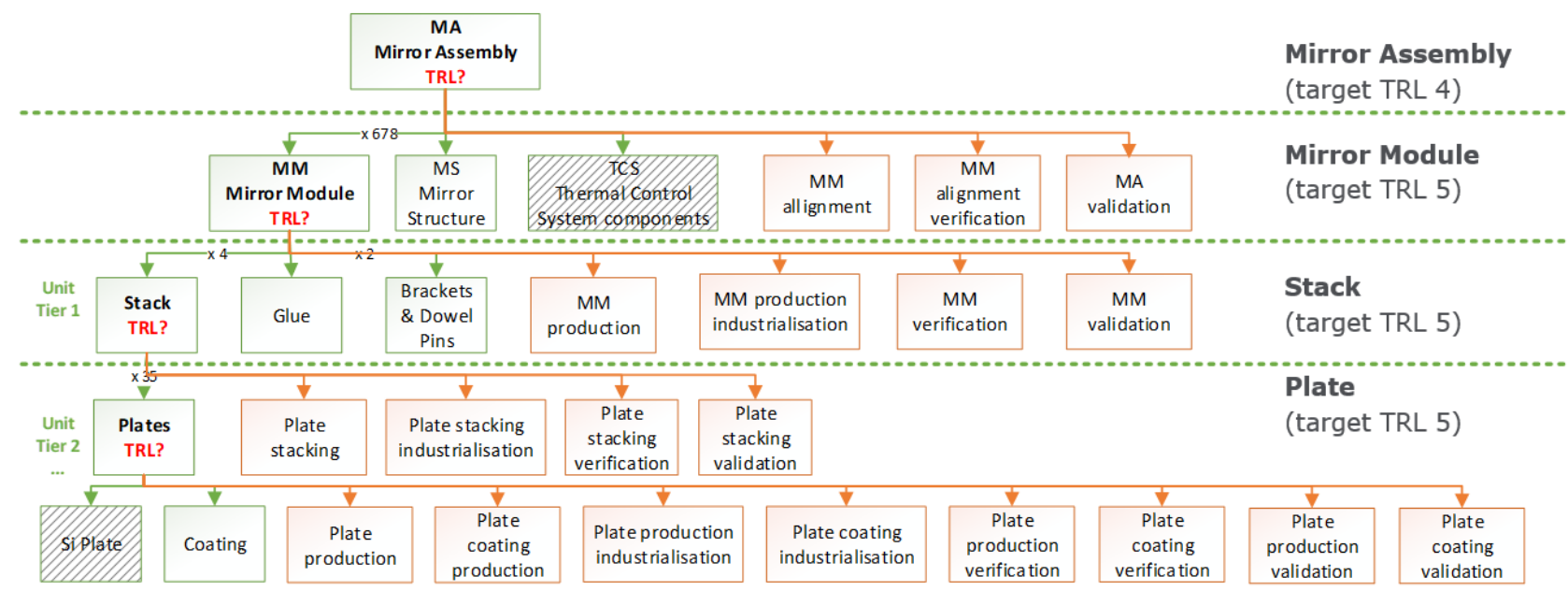

Figure 6: Critical aspects of the ATHENA optics (products in green, processes in orange, and non-critical elements are greyed out).

For each one of these four levels, a TRA form was filled, targeting a given TRL number. For the Plate, Stack and Mirror Module a TRL of 5 was targeted. For the Mirror Assembly, since the level of maturity is lower, a TRL of 4 was targeted.

Note that the critical aspects are not only related product but also processes, e.g. the assessment of the TRL of the Mirror Module addressed not only the Stacks, Glue, Brackets and Dowel Pins, but also the production, verification, validation and industrialisation (figure 7). 


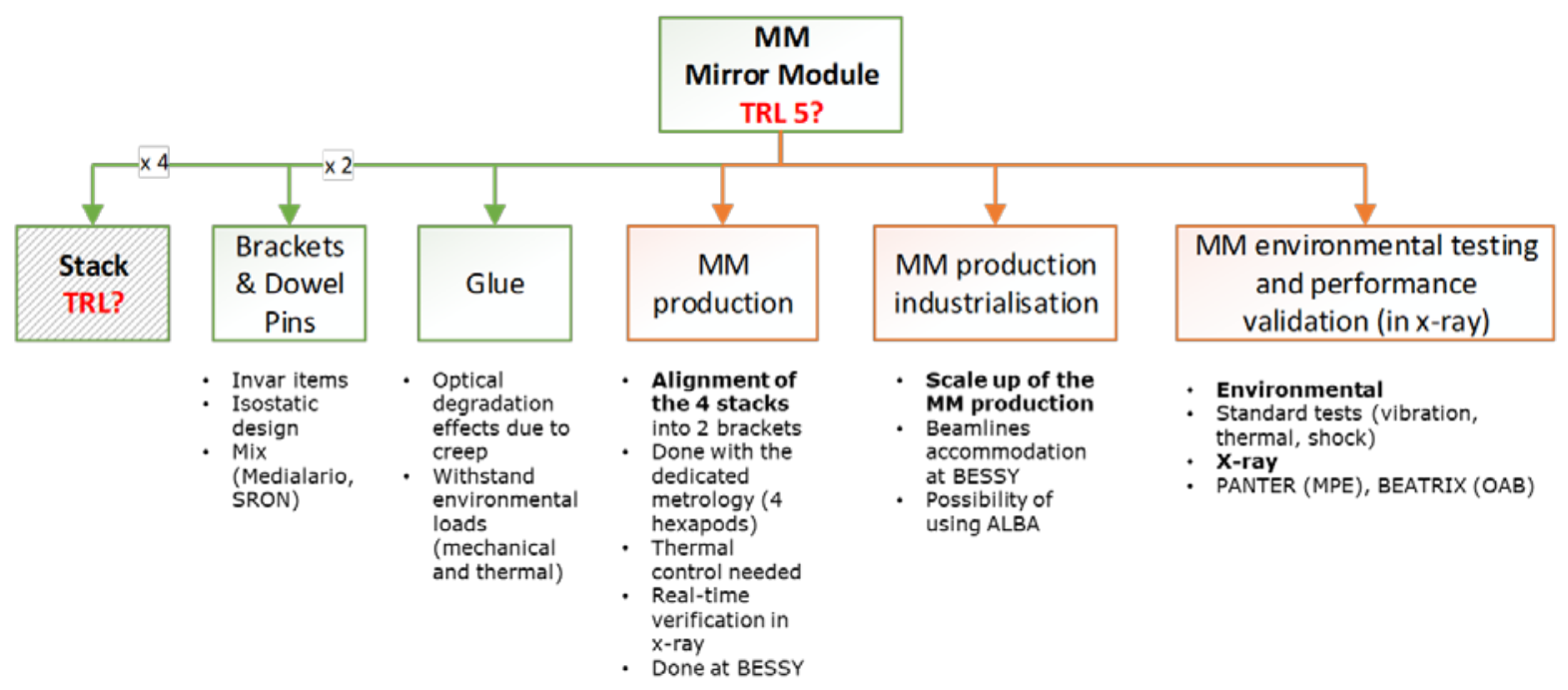

Figure 7: Example of the decomposition of the Mirror Module TRA assessment into related products and processes

Establishing an objective exercise was an essential requirement of the assessment. Therefore, a dedicated TRA form was prepared considering the ISO 16290 standard on "Space systems - Definition of the Technology Readiness Levels (TRLs and their criteria of assessment)" [62]. Particularly, the experience from CNES performing similar exercises and the guidelines established in the ECSS-E-HB-11A handbook (ESA guidelines on the implementation of the ISO 16290 standard) were considered in order to compile a number of questions that could be answered in a Boolean way.

The analysis of the optics TRA report will be done during the MFR but the initial analysis shows that the developments are in line with the expected maturity level at the end of Phase A.

\section{SMOOTH EVOLUTION INTO FLIGHT PRODUCTION}

The technological preparation of the ATHENA optics always followed a holistic approach, considering not only the performance, but also the environmental compatibility and the industrialisation aspects. The benefits of this approach is becoming more evident as the mission approaches the MFR and soon the MAR. The transition from the study and technology preparation phase in to the mission implementation phase is therefore evolutionary in nature, and does not require disruptive changes.

Mirror plates are already being made from readily available and low cost Silicon wafers, using industrial processes and equipment (see figure 8). Future flight model quality assurance requirements are already being considered, and, e.g., each single mirror plate is laser labelled with a unique identifying code. Currently, about 2000 mirror plates are being produced per year, defined by the number of plates required for the development activities, and the production rate can be increased without major modifications.

The mirror plates are mounted by bonding them to stacks using automated robots with integrated figure metrology, logging the quality of the mirror plates in the course of production. The operator controlling the stacking process is located in a control room located outside the clean room. Four independent stacking robots are currently available, each able to mount one mirror plate every 10 to 15 minutes.

Four mirror stacks are assembled to a mirror module using synchrotron radiation, and a fully equipped dedicated beamline is available in the Physikalisch-Technische Bundesanstalt (PTB) laboratory at BESSY-II in Berlin, and other beamlines are available for characterisation [63, 64]. Implementation of a back-up beamline at the ALBA facility near 
Barcelona is being prepared. The processes and procedures used today are applicable for the flight model production, and the location of further required two beamlines at the PTB laboratory at BESSY-II is already identified and reserved.

Further facilities are being used, designed or implemented, like the PANTER long beam facility of the Max-PlanckInstitut für extra-terrestrische Physik located near Munich, or the Beam Expander Testing X-ray facility (BEaTriX) in Merate near Milano [65-70]. Environmental test equipment is available for simulating the specific ATHENA optics requirements [71].
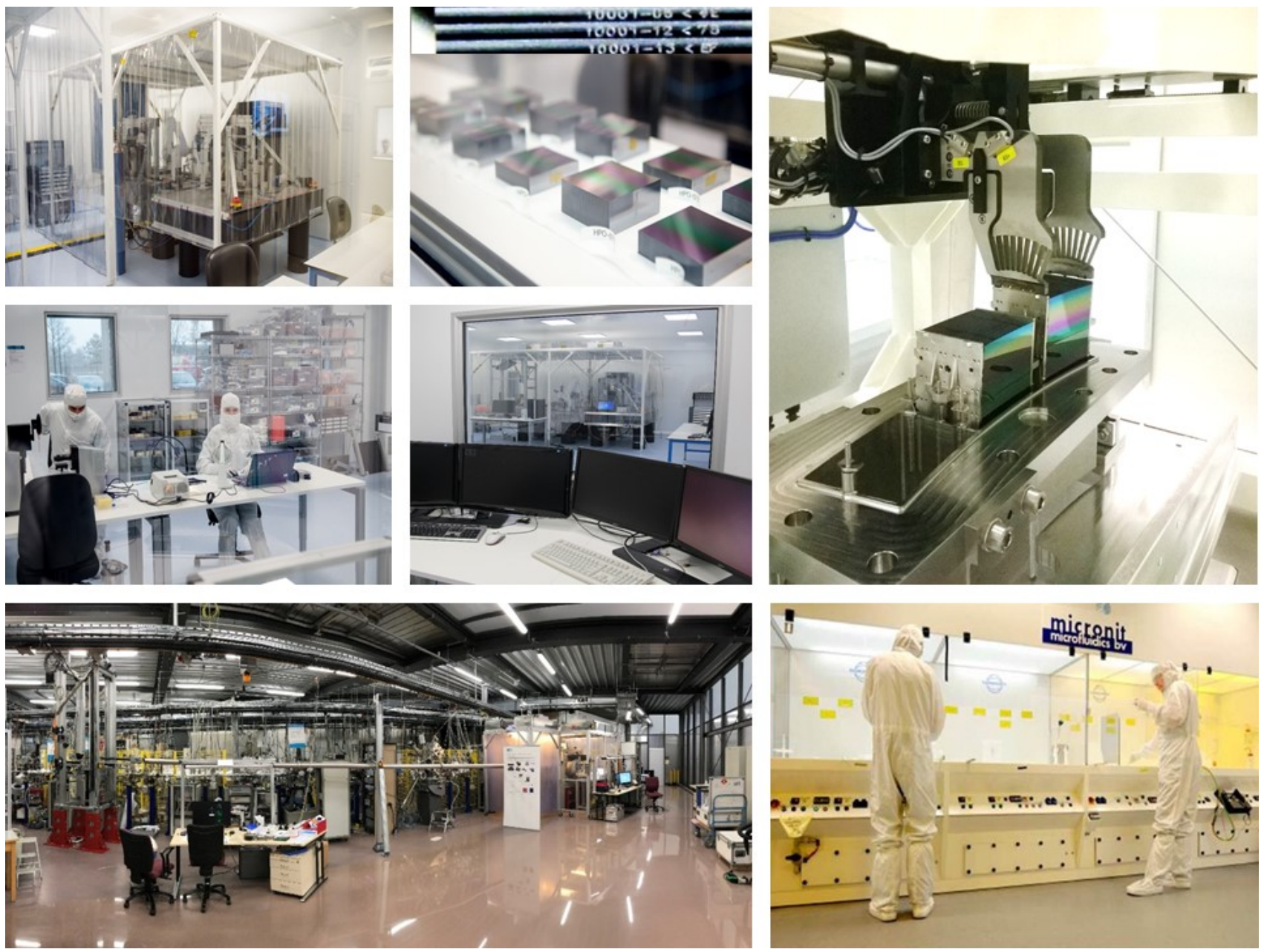

Figure 8: The production of the ATHENA optics is already largely automated and up-scalable for the production of the flight units. Clockwise from top left: stacking robot in clean tent inside the clean room, mirror plate stacks (insert showing individually labelled mirror plates), mirror modules being integrated into the optical bench, industrial facility used to produce mirror plates, Xray beamline at the BESSY-II synchrotron facility, goods-incoming inspection cleanroom at cosine, and at the center: control room for stacking operations.

Implementation of the mirror module integration facility has started, and the $2.6 \mathrm{~m}$ diameter UV collimator is being procured (figure 9). The Zerodur blank has been cast and machined to $50 \mu \mathrm{m}$ figure error by Schott AG in Germany, and shipped to Opteon Oy in Finland for further processing. This facility will be used to integrate the mirror modules (about 700 of them) into the Mirror Assembly Structure of ATHENA. 


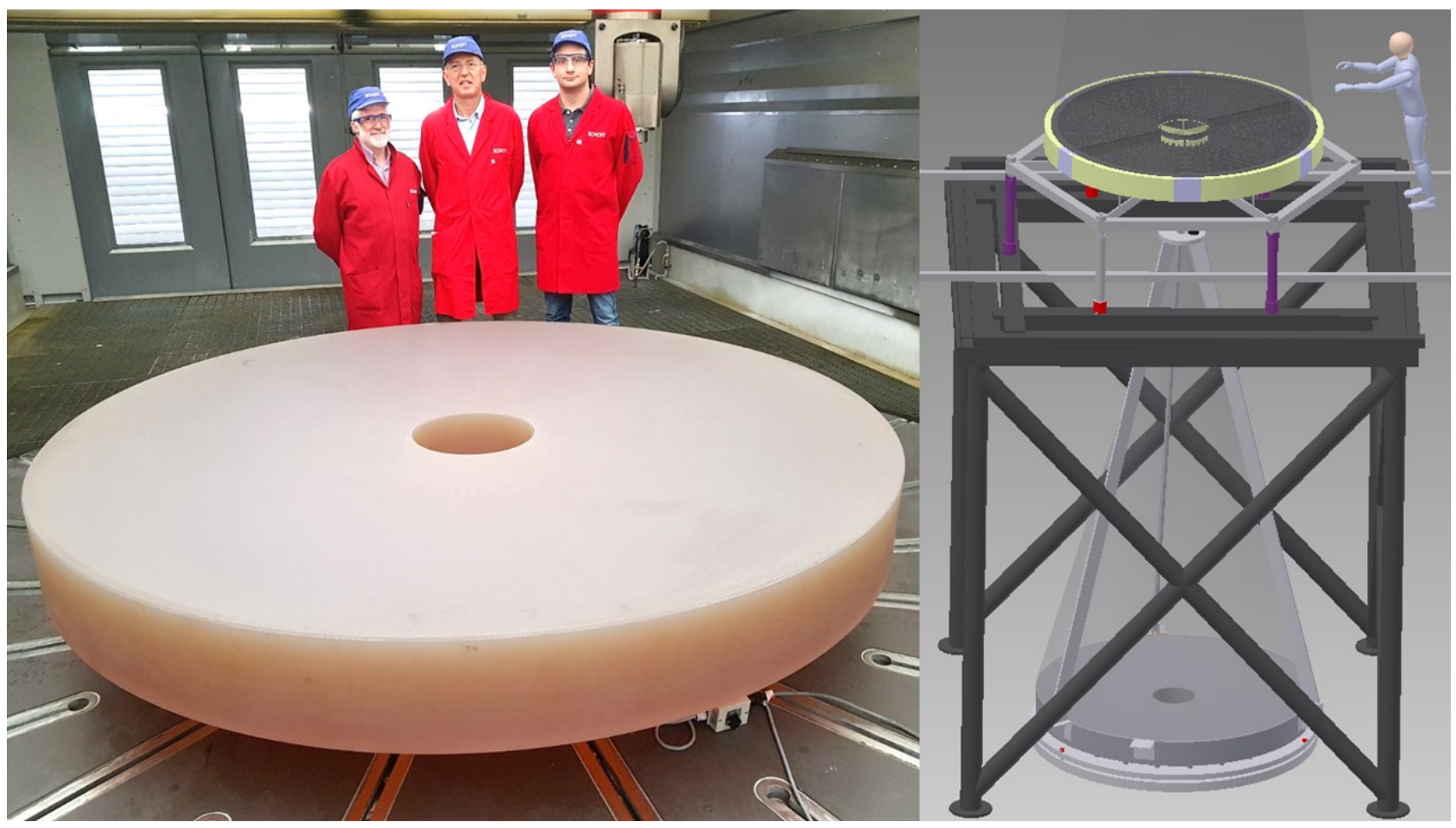

Figure 9: Left: Zerodur blank of 2.6 m diameter, machined by Schott AG to $50 \mu$ m figure error, ready for shipment to Opteon Oy for lapping, polishing and final figuring. This long-lead item is a key element of the mirror module integration facility currently being implemented at Media Lario S.r.l. Right: sketch of the UV collimator using the $2.6 \mathrm{~m}$ mirror to produce a collimated vertical beam, serving to accurately position the mirror modules during integration into the Mirror Assembly Structure of ATHENA.

\section{CONCLUSION}

The development of the ATHENA optics is progressing further, addressing all elements, ranging from mirror plates and modules, over environmental and X-ray testing to facility preparation and series production. A fully funded Technology Plan is being implemented, complemented by activities funded by the Member States, in particular The Netherlands and Germany.

The demonstrated measured angular resolution of the optics is improving steadily, and a good understanding of the error terms was achieved. Work is advancing in addressing each of the factors contributing to the improvement of the angular resolution. A major achievement was the successful demonstration of the ability to remove the lateral sides of the mirror stacks, effectively removing the most dominant error terms. Mirror stacks will be originally produced with over-width, resulting in the nominal required width after removal of the sides. In essence, the HEW measured over $70 \%$ of the mirror module area becomes the new $100 \%$.

The technology readiness is being formally assessed, in a well-defined process, and closely linked and embedded in the ATHENA mission reviews.

With the anticipated adoption date for the ATHENA mission approaching fast, the planning and implementation of the required flight implementation facilities has started. Some of the equipment used to produce the ATHENA optics mirror modules is already capable of flight production rates, and all processes, materials and equipment are compatible with the required upscaling. Investment in long lead items for the required production, assembly and testing facilities has started and the implementation of the full scale ATHENA mirror assembly module AIT facility has commenced. 


\section{ACKNOWLEDGEMENTS}

The authors greatly appreciate the collaborative spirit of the collaboration, and would like to express their thanks to all those involved in the endeavour to develop the optics for the ATHENA mission.

\section{REFERENCES}

[1] Nandra, P. et al, “ATHENA : The Advanced Telescope for High-Energy Astrophysics”, http://www.the-ATHENA-x-rayobservatory.eu/

[2] Ayre, M., et al, “ATHENA - System design and implementation for a next generation x-ray telescope”, Proc. of SPIE Vol. 9601, 96010L (2015)

[3] Ayre, M., et al, “ATHENA: system studies and optics accommodation”, Proc. SPIE 9905, 990526 (2016)

[4] Ayre, M., et al, “ATHENA - System design and implementation for a next generation x-ray telescope”, Proc. of SPIE Vol. 10397, 103970X-2 (2017)

[5] Ayre, M., et al, “ATHENA: system studies and optics Accommodation”, Proc. of SPIE Vol. 10699, 106991E (2018)

[6] Beijersbergen, M. et al., "Development of x-ray pore optics: novel high-resolution silicon millipore optics for XEUS and ultralow mass glass micropore optics for imaging and timing", Proc. SPIE 5539, 104-115 (2004).

[7] Beijersbergen, M. et al., "Silicon pore optics: novel lightweight high-resolution X-ray optics developed for XEUS", Proc. SPIE 5488, 868-874 (2004).

[8] Kraft, S. et al., "Development of modular high-performance pore optics for the XEUS x-ray telescope", Proc. SPIE 5900, 297-308 (2005).

[9] Günther, R. et al., "Production of silicon pore optics", Proc. SPIE 6266, 626619 (2006).

[10] Collon, M. J. et al., "Performance characterization of silicon pore optics", Proc. SPIE 6266, 62661T (2006).

[11] Collon, M. J. et al., "Metrology, integration, and performance verification of silicon pore optics in Wolter-I configuration", Proc. SPIE 6266, 626618 (2006).

[12] Graue, R. et al., "Assembling silicon pore optics into a modular structure", Proc. SPIE 6266, 62661U (2006).

[13] Wallace, K. et al, “Silicon pore optics development”, Proc. SPIE 7437, 7437 (2009)

[14] Kampf, D. et al., “Optical bench elements (petals) for IXO”, Proc. SPIE, 7437 (2009)

[15] Collon, M. J. et al, "Stacking of silicon pore optics for IXO”, Proc. SPIE, 7437 (2009)

[16] Ackermann, M et al, "Performance prediction and measurement of silicon pore optics”, Proc. SPIE, 7437 (2009)

[17] Vacanti, G, et al., "Silicon pore optics for astrophysical missions”, Proc. SPIE, 7732, 773240 (2010)

[18] Collon, M. J. et al, “Silicon Pore X-ray Optics for IXO”, Proc. SPIE 7732, 77321F (2010)

[19] Bavdaz, M., “ESA optics technology preparation for IXO”, Proc. SPIE 7732, 77321E (2010)

[20] Wille, E, et al, "Mass Production of Silicon Pore Optics for IXO and ATHENA", Proc. of SPIE 8147, 81470E1(2011)

[21] Collon, M, et al, "Design, Fabrication, and Characterization of Silicon Pore Optics for ATHENA/IXO", Proc. of SPIE 8147, 81470D1(2011)

[22] Bavdaz, M. et al., "ESA led ATHENA/IXO optics development status”, Proc. of SPIE 8147, 81470C1(2011)

[23] Bavdaz, M, et al, "Silicon Pore Optics developments and status", Proc. of SPIE 8443, 844329(2012)

[24] Ackermann, M, et al, "Novel applications of Silicon Pore Optics technology", Proc. of SPIE 8443, 84430V(2012)

[25] Bavdaz, M., et al, "X-ray optics developments at ESA”, Proc. of SPIE Vol. 8861, 88610L (2013)

[26] Collon, M., et al, “Aberration-free Silicon Pore X-ray Optics”, Proc. of SPIE Vol. 8861, 88610M (2013)

[27] Wille, E., et al, "Stray Light Baffling and Environmental Qualification of Silicon Pore Optics", of SPIE Vol. 8861, 88611E (2013)

[28] Willingale, R. et al, "Science requirements and optimization of the silicon pore optics design for the ATHENA mirror", Proc. of SPIE Vol. 9144, 91442E (2014)

[29] Bavdaz, M. et al, "Preparing the optics technology to observe the hot universe”, Proc. of SPIE Vol. 9144, 91442F (2014)

[30] Collon, M. et al, "Making the ATHENA optics using Silicon Pore Optics", Proc. of SPIE Vol. 9144, 91442G (2014)

[31] Wille, E. et al, "Qualification of Silicon Pore Optics", Proc. of SPIE Vol. 9144, 91442H (2014)

[32] Bavdaz, M. et al, "The ATHENA Optics”, Proc. of SPIE Vol. 9603, 96030J (2015)

[33] Collon, M. et al, "Silicon Pore Optics development for ATHENA", Proc. of SPIE Vol. 9603, 96030K (2015)

[34] Wille, E. et al, "Silicon Pore Optics Mirror Modules for Inner and Outer Radii", Proc. of SPIE Vol. 9603, 96030L (2015)

[35] Vacanti, G., et al, "New ray-tracing capabilities for the development of Silicon Pore Optics", Proc. of SPIE Vol. 9603, 96030G (2015) 
[36] Della Monica Ferreira, D. et al., “Coating Optimisation for the ATHENA+ mission”, Proc. Of SPIE Vol.8861, 886112 (2013)

[37] Massahi S., et al, "Investigation of Photolithography Process on SPOs for the ATHENA Mission”, Proc. of SPIE Vol. 9603, 96030M (2015)

[38] Bavdaz, M., et al, “The ATHENA optics development”, Proc. SPIE 9905, 990527 (2016)

[39] Collon, M., et al, “Silicon pore optics for the ATHENA telescope”, Proc. SPIE 9905, 990528 (2016)

[40] Wille, E., et al, "Mass production of silicon pore optics for ATHENA”, Proc. SPIE 9905, 990529 (2016)

[41] Spiga, D., et al, "Simulation and modelling of silicon pore optics for the ATHENA x-ray telescope", Proc. SPIE. 9905, 990550 (2016)

[42] Bavdaz, M., et al, “The ATHENA telescope and optics status”, Proc. of SPIE Vol. 10399, 103990B-1 (2017)

[43] Collon, M., “Development of ATHENA mirror modules”, Proc. of SPIE Vol. 10399, 103990C-1 (2017)

[44] Valsecchi, G., et al, "Optical integration of SPO mirror modules in the ATHENA telescope”, Proc. of SPIE Vol. 10399, 103990E-1 (2017)

[45] Vernani, D., et al, "Integration of the ATHENA mirror modules: development of indirect and X-ray direct AIT methods", Proc. of SPIE Vol. 10399, 103990F-1 (2017)

[46] Vacanti, G., et al, "Predicting Silicon Pore Optics”, Proc. of SPIE Vol. 10399, 103990M-1 (2017)

[47] Landgraf, B., et al, "Environmental testing of the ATHENA mirror modules”, Proc. of SPIE Vol. 10399, 103990G-1 (2017)

[48] Della Monica Ferreira, D. et al., "Design, development, and performance of X-ray mirror coatings for the ATHENA mission”, Proc. of SPIE Vol. 10399, 1039918-1 (2017)

[49] Massahi, S., et al, "Industrialization of the mirror plate coatings for the ATHENA mission", Proc. of SPIE Vol. 10399, 103991W-1 (2017)

[50] Bavdaz, M., et al, “Development of the ATHENA Mirror”, Proc. of SPIE Vol. 10699, 106990X (2018)

[51] Collon, M., et al, "Silicon Pore Optics Mirror Module Production and Testing”, Proc. of SPIE Vol. 10699, 106990Y (2018)

[52] Valsecchi, G., et al, "Results of silicon pore optics mirror modules optical integration of the ATHENA telescope", Proc. of SPIE Vol. 10699, 106990Z (2018)

[53] Fioretti, V., et al, "The Geant4 mass model of the ATHENA Silicon Pore Optics and its effect on soft proton scattering", Proc. of SPIE Vol. 10699, 106993J (2018)

[54] Della Monica Ferreira, D. et al., "Performance and Stability of Mirror Coatings for the ATHENA Mission”, Proc. of SPIE Vol. 10699, 106993K (2018)

[55] Wille, E., et al, "Silicon pore optics manufacturing plan and schedule for ATHENA", Proc. of SPIE Vol. 10699, 106993L (2018)

[56] Vernani, D., et al, "Integration of the Athena mirror modules: development status of the indirect and direct X-ray methods”, Proc. of SPIE Vol. 10699, 1069910 (2018)

[57] Collon, M., et al, “Silicon Pore Optics Mirror Module Production and Testing”, Proc. of SPIE Vol. 11180, 1118023 (2018)

[58] Valsecchi, G., et al, “ATHENA Telescope: alignment and integration of SPO mirror modules”, Proc. of SPIE Vol. 11180, $111801 \mathrm{~N}(2018)$

[59] O’Dell, S.L. and M. C. Weisskopf ,“Advanced X-ray astrophysics facility (AXAF): Calibration overview”, Proc. SPIE 3444 (1998) and references therein

[60] Jansen, F. et al., "XMM-Newton observatory", Astron. Astrophys. 365, L1-L6 (2001)

[61] William W. Craig, et al., "Fabrication of the NuSTAR Flight Optics”, Proc. of SPIE Vol. 8147, 81470H (2011)

[62] ISO, "Space systems - Definition of the Technology Readiness Levels (TRLs) and their criteria of assessment”, ISO 16290, The International Organization for Standardization (2013)

[63] Krumrey, M. et al, “X-ray pencil beam facility for optics characterization”, Proc. SPIE 7732, 773240 (2010)

[64] Krumrey, M. et al, “New X-ray parallel beam facility XPBF 2.0 for the characterization of silicon pore optics”, Proc. SPIE. 9905, 99055N. (2016)

[65] Freyberg, M. et al., "Potential of the PANTER x-ray test facility for calibration of instrumentation for XEUS", Proc. SPIE 6266, 62663H (2006)

[66] Burwitz, V., et al, "In focus measurements of IXO type optics using the new PANTER X-ray test facility extension”, Proc. of SPIE Vol. 8861, 88611J (2013)

[67] Burwitz, V. et al., "Developing, testing, and calibrating the ATHENA optics at PANTER”, Proc. SPIE 10399, 1039900 (2017) 
[68] Salmaso, B., et al, "Progress in the realization of the Beam Expander Testing X-ray facility (BEaTriX) for testing ATHENA’s SPO modules”, Proc. of SPIE Vol. 10699, 106993I (2018)

[69] Burwitz, V., et al, "X-ray Testing at PANTER of Optics for the ATHENA and Arcus Missions”, Proc. of SPIE Vol. 11180, 1118024 (2018)

[70] Salmaso, B., et al, "BEaTriX (Beam Expander Testing X-ray facility) for testing ATHENA's SPO modules: advancement status”, Proc. of SPIE Vol. 11180, 1118026 (2018)

[71] Fransen, S. et al, "Prediction of the mechanical environments of the load critical elements of the ATHENA spacecraft", Proc. 15th European Conference on Spacecraft Structures, Materials and Environmental Testing (2018) 